\title{
ESTRATÉGIAS DE ESTUDOS NA EDUCAÇÃO FÍSICA À DISTÂNCIA:UM ESTUDO PILOTO QUANTO ÀS PREFERÊNCIAS DE APRENDIZAGEM DOS ACADÊMICOS.
}

CURITIBA/PR MAIO/2018

\author{
Sidney Gilberto GoncalvesII - UNiNTER - sidney.g@uninter.com \\ KETYLEN DE JESUS DOS SANTOS \\ - UNINTER - KETYLEN-SANTOS@BOL.COM.BR \\ LUCAS DIEGO DA CRUZ \\ - UNINTER - MASCOTI_@OUTLOOK.COM
}

Tipo: Investigação Científica (IC)

Natureza: Planejamento de Pesquisa

Categoria: Pesquisa e Avaliação

Setor Educacional: EDUCAÇÃO SUPERIOR

\begin{abstract}
RESUMO
A pesquisa possui como tema central uma aproximação mais direta para com o aluno, buscando entender as estratégias de aprendizagem na educação física a distância e suas preferências de estudos, seguindo sua crescente expansão no cenário acadêmico. Destaque-se como objetivo quais as preferências de estudos dos acadêmicos e específico seus hábitos e estratégias de aprendizagem. (2) descrever os resultados encontrados a partir de questionários aplicados com alunos do curso à distância de bacharelado em educação física da UNINTER; como sendo um estudo piloto, esta pesquisa parcial apresenta uma discussão dos resultados obtidos, por meio de questionário com 17 preferências de estudos aplicado aos alunos, totalizando 41,7\% de respondentes, de um grupo de 139 acadêmicos. As análises dos resultados indicam o que atualmente os alunos têm como preferências para seus hábitos e estratégias de estudos. Cabem aos profissionais da educação estarem sempre atentos as demandas de aprendizagem, sendo assim criativos na elaboração de novas preferências de estratégias cognitivas que possam auxiliar no melhor e eficaz aprendizado dos acadêmicos.
\end{abstract}

Palavras-chave: EaD; Estratégias; Educação Física.

\section{AGRADECIMENTOS}




\section{Introdução}

Os cursos de graduação em Educação Física à distância se constituem enquanto uma realidade no Brasil, embora seja objeto de grande resistência. Dados do Ministério da Educação indicam a existência de 40 cursos em funcionamento (12 de bacharelado e 28 de licenciatura) em junho de 2017, com um número de vagas autorizadas na ordem de 121 mil por ano (64 mil na licenciatura e quase 57 mil no bacharelado). Como elemento de comparação, em 1494 cursos na modalidade presencial, o total de vagas ofertadas resulta em aproximadamente 220 mil por ano (sendo 103 mil no bacharelado e 117 mil na licenciatura).

Ou seja, no ano de 2017, pouco mais de um terço das vagas em cursos de Educação Física no Brasil são ofertadas a distância, sendo que o número de cursos a distância representa apenas $2 \%$ do total. Das 32 instituições de ensino superior que oferecem os 40 cursos a distância, 6 são públicas e 26 são privadas (MINISTÉRIO DA EDUCAÇÃO, 2017).

Assim, o problema que se apresenta para essa pesquisa é o seguinte: quais são os hábitos e estratégias de estudos que os alunos dos cursos de bacharelado em Educação Física à distância do Centro Universitário Internacional - UNINTER tem como preferência para atingir os objetivos de aprendizagem e retenção do conhecimento neste curso?

\section{Objetivo}

Coloca-se como objetivo geral identificar quais as preferências de estudos dos acadêmicos na Educação Física à distância (EDF- AD) e como objetivos específicos: (1) observar os hábitos e estratégias de estudos na EDF- AD; (2) descrever os resultados encontrados a partir de questionários aplicados aos alunos do curso de bacharelado em EDF.

\section{Referencial Teórico}

\section{Educação à Distância e Tecnologias em Informação e Comunicação (Tic's)}

A educação a distância tem como pressuposto o uso de tecnologias de informação e comunicação (TIC's), para que os alunos obtenham acesso as plataformas digitais e suas ferramentas que direcionam seus conteúdos assim o estimulando para o devido conhecimento de sua formação, de forma geral, esse acesso se dá através de 
equipamentos com conectividade a internet, em ambientes virtuais de aprendizagem que contêm artigos, livros virtuais, vídeo aulas, apresentações em slides e demais materiais produzidos pelos professores tutores.

Ainda que exista o apoio de professores tutores, tanto online quanto presencialmente, uma característica chave da educação a distância é a necessidade do desenvolvimento de autonomia por parte dos alunos, visto que se instaura uma relação de flexibilidade e independência na incorporação do conhecimento em nível superior. Nesse contexto, a identificação dos métodos e estratégias de estudo e aprendizagem utilizados pelos alunos se torna necessária, buscamos encontrar pontos comuns ou majoritários sobre características temporais e espaciais para os estudos, bem como sobre o uso das ferramentas disponíveis no ambiente virtual e fora dele para acesso e incorporação de informações. Em acompanhamento ao cronograma e entre as definições de ensino à distância (EAD) elencamos a disposta no decreto no 5622 de 19 de dezembro de 2005 (BRASIL, 2005):

[...] caracteriza-se a educação a distância como modalidade educacional na qual a mediação didático-pedagógica nos processos de ensino e aprendizagem ocorre com a utilização de meios e tecnologias de informação e comunicação, com estudantes e professores desenvolvendo atividades educativas em lugares ou tempos diversos.

\section{Hábitos de Estudo: Uma Visão da Literatura Científica}

O ensino a distância tem aumentado seu espaço no cenário acadêmico nacional proporcionando o ingresso no ensino superior. EAD (Educação Aberta a Distância) oportuniza o estudo a nível superior a um número maior de brasileiros que tem como sala de estudos, um ambiente virtual que não necessariamente precisa ser na universidade. Para isso, o uso da tecnologia, de estratégias de estudos torna-se necessário para que se atinjam os objetivos de estudos e realmente se aprenda. Maturano e Lemes (2012) corroboram cientificando que "nesta conjuntura, o ensino a distância atrelado ao avanço tecnológico, é um importante auxiliar do processo educativo, podendo ser utilizado com proficuidade no enriquecimento dos cursos de formação discentes e docentes". Éde fundamental relevância os recursos pedagógicos de ensino/aprendizagem, sendo elas atividades síncronas ou assíncronas, ou seja, atividades realizadas simultaneamente com seus pares a nível moodle ou em atividades que possam ser realizadas indistintamente do estado de interação no dado momento. A importância de um tutor neste processo de ensino aprendizado mediado por tecnologias, para desenvolver a orientação, o incentivo, o atendimento individualizado, o suporte tecnológico e o estímulo, auxiliando nestas estratégias de estudos para o sucesso do discente. 
Neste sentido Silveira et a. (2012) descreve o papel atual do educador é centrar-se no incentivo a aprendizagem e o pensamento, tornando-se um animador da inteligência coletiva dos grupos que estão sob a sua coordenação. Sua atividade principal será o acompanhamento e gestão das aprendizagens, incentivando a troca de saberes, mediação das relações e dos percursos de aprendizagem.

Como já visto, a metodologia EaD é considerada uma forma mais flexível, porém requer diferentes atitudes e comportamentos dos discentes que dela fazem parte. Entre os alunos, espera-se que possam agir independentemente, refletir sobre a própria aprendizagem e controlá-la (FARIA, 2010), ou seja, requer indivíduos autônomos, competentes e críticos. Nesse sentido, o uso das estratégias de aprendizagem torna-se uma excelente ferramenta para que eles conheçam e regulem sua própria cognição.

\section{Estratégias de aprendizagem nos estudos a distância.}

Agora precisam de estratégias eficazes para cumprir o cronograma de estudos no ambiente virtual. Para Peters (2004, p. 379), [...] isso é expresso simplesmente pelo fato de que os alunos trabalham em relativo isolamento dos outros e que todas as atividades na aquisição do conhecimento têm que ter início neles mesmo [...], ou seja, os alunos se tornam os principais envolvidos dentro do processo de ensino aprendizagem.

A melhor estratégia de estudo/aprendizagem terá que ser desenvolvida pelo discente, por meio das dicas que seus tutores possam lhes propor tal qual no caso de uma disciplina presencial e, da mesma forma, muitas vezes é reconstruído no desenrolar do curso, porém os alunos precisam ser dinâmicos em estabelecer estratégias que sejam eficazes, pois o curso está se desenvolvendo e o que não é interessante a tal "bola de neve" dos conteúdos que se apresentam no ambiente virtual.

De acordo com Warr e Allan (1998, apud ZERBINI; PILATI, 2012, p. 228):

\footnotetext{
Estratégias de aprendizagem são procedimentos e capacidades cognitivas complexas, aprendidas ao longo da vida, seja naturalmente ou por meio de treino, utilizadas pelos indivíduos em atividade de aprendizagem que facilitam o alcance de todos os critérios da aprendizagem.
}

Nesta pesquisa, o Fator 1 do Questionário de Hábitos de Estudos contém itens de questões que permitem investigar essa dimensão didática da autonomia apontada por Peters (2006). Pouco ainda se sabe sobre o perfil do aluno a distância, frente que carece de pesquisas em outros contextos e cenários, afinal, saber quem é o aluno virtual e quais são suas demandas e características ajuda a planejar cursos mais apropriados para atender suas necessidades, principalmente aqueles com foco no aluno, pois preparar um curso nesse contexto significa pensar num processo que promova seu crescimento, pois, 
[...] [n]este clima que promove o crescimento, a aprendizagem é mais profunda e se desenvolve num ritmo mais rápido, sendo mais útil para a vida e para o comportamento do aluno, do que a aprendizagem adquirida na sala de aula tradicional. Isso acontece porque a direção é auto escolhida, a aprendizagem é autodidata e a pessoa como um todo, com sentimentos e paixões tanto quanto com o intelecto, é envolvida no processo (ROGERS, 1989, $p$. 79).

\section{Procedimentos Metodológicos}

A partir dessa proposta, a presente pesquisa se caracteriza como um estudo piloto quantitativo por meio de levantamento de dados estatísticos advindos da aplicação de questionário online e presencial, para acadêmicos de EDF - AD, cujas respostas foram tratadas pela estatística descritiva (distribuição percentual e comparação entre respostas). Da questão elaborada aos respondentes, foram elencados 17 itens abordando as preferências que utilizam para seus estudos. Sendo eles virtual (Ava) ou físicos, locais mais convenientes à esta prática e períodos destinados no dia a dia. Foram utilizados email, rede social e impressos para que os alunos do Bacharelado respondessem a pesquisa. Dos 139 acadêmicos ativos, apenas 58 respondentes contribuíram o que representou $41,7 \%$ que contribuíram com a pesquisa.

\section{Apresentação e Discussão dos Resultados}

Identificamos com as pesquisas que existiu um número maior de respondentes do sexo masculino como indica o gráfico1. 

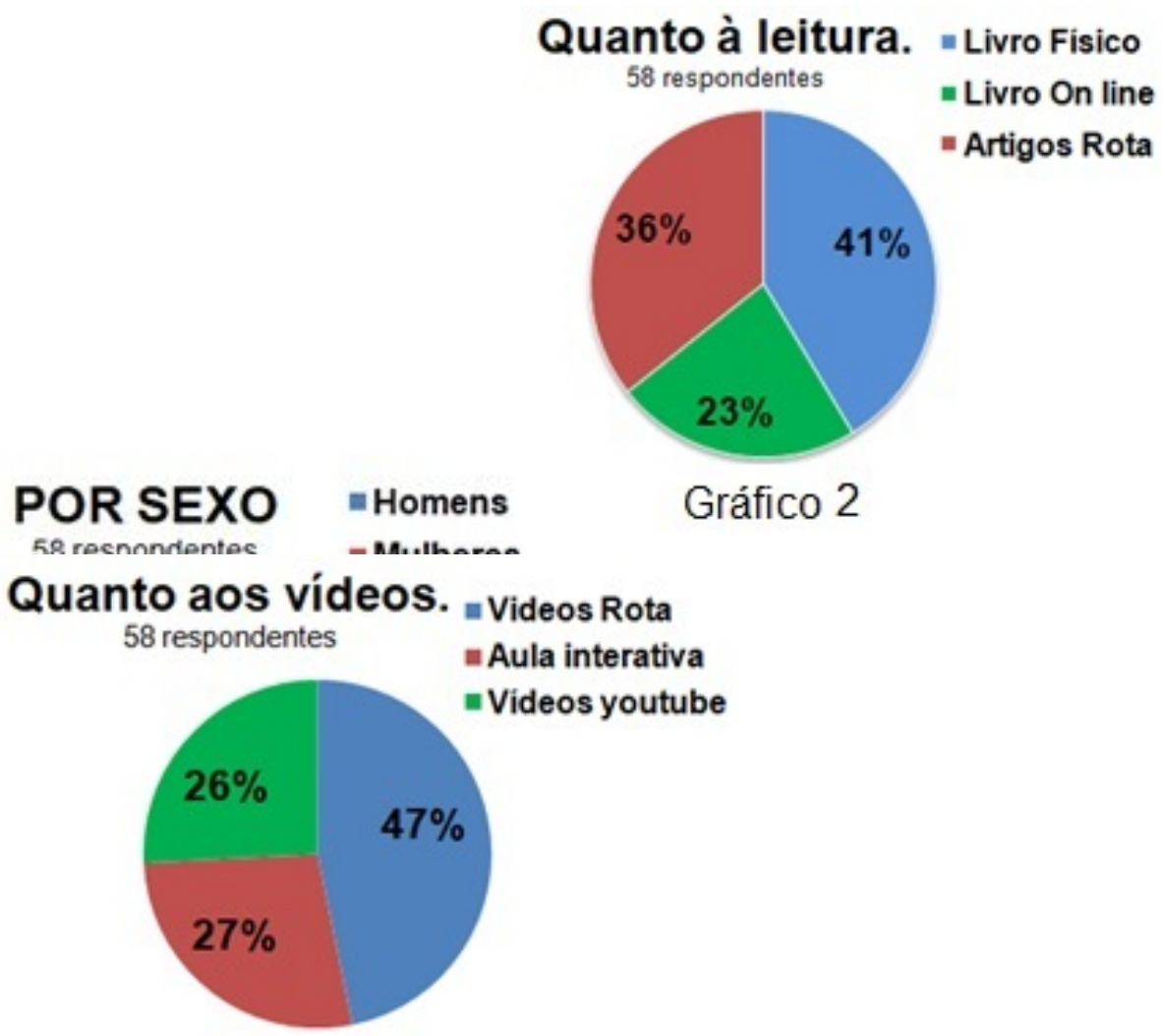

Gráfico 3

Para a análise do gráfico 2, os academicos mencionaram ser de preferência, a leitura física como maior estratégia para assimilação e complementação dos conteúdos abordados na fase de estudo, com relatos de que ainda a leitura on line é um pouco cansativa frente a física, pois no papel, pode-se fazer anotações, pontuar e marcar as partes mais relevantes aos estudos.

Como forma de complementar o que os alunos (as) têm na teoria, (ver Gráfico 3) a plataforma disponibiliza vídeos para entendimento dos conteúdos teóricos, indicado por $47 \%$ dos avaliados, bem como $27 \%$ disseram que as aulas interativas ao vivo, fazem parte dos estudos, na qual os acadêmicos podem interagir com os professores indagando quando houverem dúvidas. Dos participantes da pesquisa, foi observado que $26 \%$ assistem a vídeos na web, por meio da ferramenta Youtube como preferência para sua aprendizagem.

Como estratégias de aprendizagem, (ver Gráfico 4) é sugerido aos acadêmicos que façam grupos de estudos no polo, em seus dias presenciais ou não, como forma de alcançar o objetivo em comum na assimilação dos conteúdos, aja vista que debatendo sobre as mesmas dúvidas, os acadêmicos quando reunidos, podem obter de forma mais objetiva as respostas. Verificamos que $64 \%$ dos respondentes ainda estudam sozinhos quanto que $36 \%$ atribuem que estudar em grupo é uma estratégia viável de 
aprendizagem.
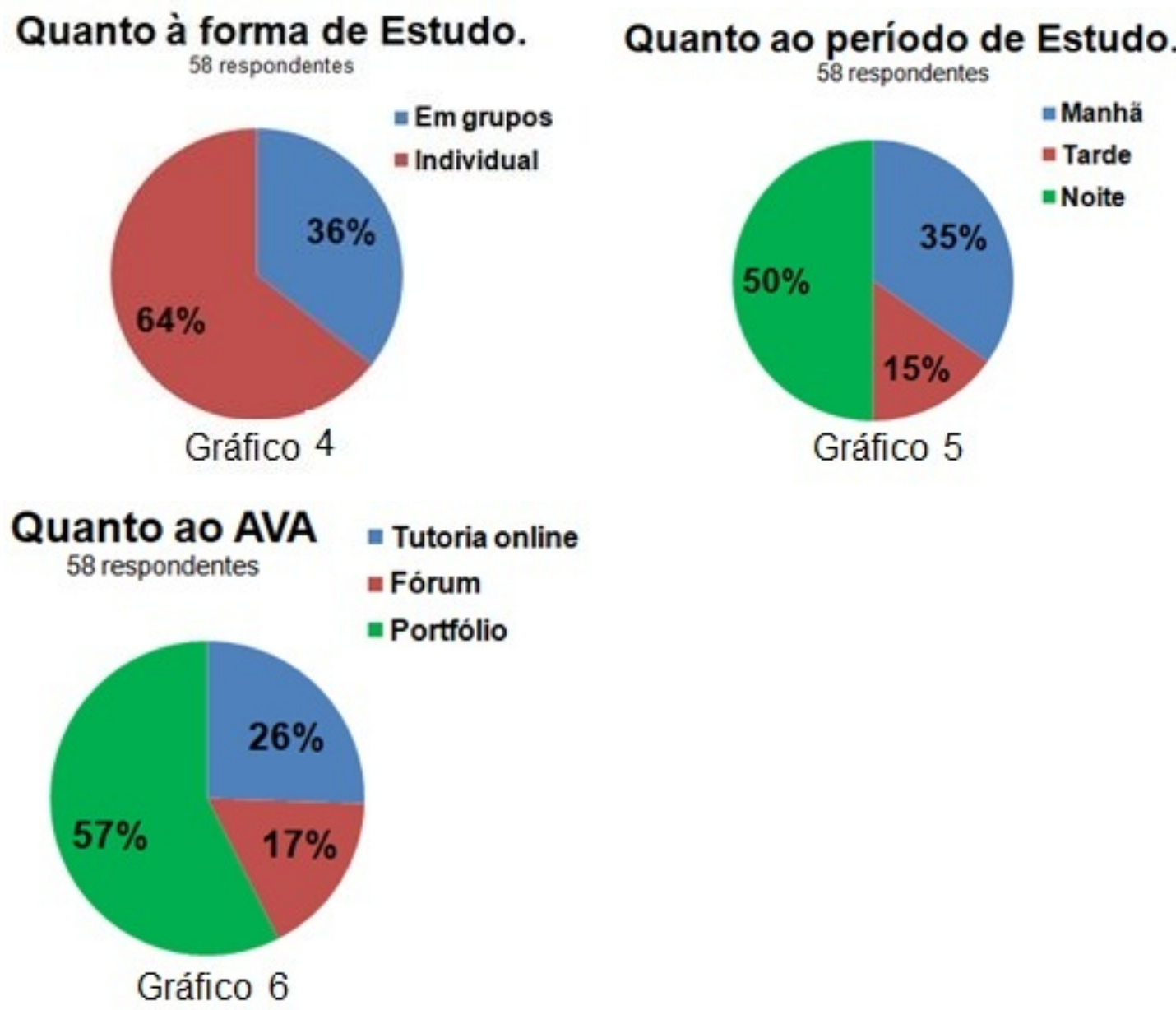

$50 \%$ dos acadêmicos apontam o período noturno como preferência de estudos (ver gráfico 5), sendo que $35 \%$ optam por estudarem pelas manhãs e apenas $15 \%$ à tarde. 0 ambiente virtual de aprendizagem (AVA) possui mais ferramentas, complementando os hábitos e estratégias de estudos dos acadêmicos, contudo (ver Gráfico 6) 57\% utilizam o portfólio como preferência, $26 \%$ dos respondentes costumam utilizar a ferramenta tutoria online para tirar dúvidas e apenas $17 \%$ dos participantes alegam que as leituras por meio do fórum auxiliam nos seus estudos.

\section{Considerações Finais}

Buscando uma excelência em aprendizagem, visando tão somente a formação de futuros profissionais capacitados e com conteúdo para exercerem as demandas que o mercado de trabalho e a sociedade exigem, a instituição de ensino à distância como uma realidade da era digital, tem que buscar soluções para atender esse novo conceito de estudos, com alunos autodidatas e pró ativos, capacidades estas observadas pelos empregadores que visam profissionais integrados e que busquem o conhecimento em suas empresas. 
Promover as mais eficientes formas de estudos ainda são um dos principais quebracabeças de instituições de ensino superior.

Os tutores presenciais buscam orientar os acadêmicos para que em pouco tempo possam estar inseridos na plataforma virtual a fim de que os conteúdos sejam absorvidos e retidos em curto prazo.

Com essas preferências de estratégias de aprendizagem disponíveis aos acadêmicos as instituições superiores de EF EAD, podem auxiliar os vários perfis de alunos, como os que trabalham durante $\mathrm{o}$ dia $\mathrm{e}$ a noite em escala, atletas que competem $\mathrm{e}$ constantemente estão em viagens, alunos (as) que vieram do ensino presencial tradicional ou que estão a um longo período fora do ambiente de estudo e ainda aos resistentes às novas tecnologias virtuais de aprendizagem.

Como sendo um projeto piloto e em construção, cabem aos profissionais da educação estarem sempre atentos as demandas de aprendizagem, sendo assim criativos na elaboração de novas preferências de estratégias cognitivas que possam auxiliar no melhor e eficaz aprendizado dos acadêmicos virtu-presenciais.

\section{Referências}

BRASIL. Decreto № 5.622, de 19 de dezembro de 2005. Regulamenta o art. $\underline{80}$ da Lei no 9.394, de 20 de dezembro de 1996, que estabelece as diretrizes e bases da educação nacional. Diário Oficial da República Federativa do Brasil,Brasilia, D.F.,19 dez. 2005.

BRASIL. Lei no 9.394, de 20 de dezembro de 1996. Estabelece as diretrizes e bases da educação nacional. Brasília, 20 dez. 1996. Disponível em: . Acesso em: 23 ago. 2017.

. Lei no 13.005, de 25 de junho de 2014. Aprova o Plano Nacional de Educação PNE e dá outras providências. Brasília, 25 jun. 2014. Disponível em: . Acesso em: 23 ago. 2017.

Decreto no 9.057, de 25 de maio de 2017. Regulamenta o art. 80 da Lei no 9.394, de 20 de dezembro de 1996, que estabelece as diretrizes e bases da educação nacional. Brasília, 25 mai. 2017. Disponível em: . Acesso em: 23 ago. 2017.

MATURANO, E.C.P.L.; LEMES, S.S. Breves discussões sobre a Educação a Distância e as Políticas Públicas dos anos noventa até o momento atual. Revista Eletrônica Gestão 
\& Saúde, v.3, ed. especial, p. 1266-1280, 2012.

MINISTÉRIO DA EDUCAÇÃO. Sistema e-MEC. Disponível em: . Acesso em: 28 jun. 2017.

PETERS, O. Didática do ensino a distância. São Leopoldo: Ed. Unisinos, 2006.

SILVEIRA, L.H.S. et al. Aprendizagem colaborativa numa perspectiva de Educação sem Distância. Revista Eletrônica Gestão \& Saúde, v.3, ed. especial, p.1468-1478, 2012.

ZERBINI, T. ABBAD, G. Estratégias de aprendizagem em curso a distância: validação de uma escala. Psico USF. São Paulo, v. 13, n. 2, p.177-187, 2008. Disponível em: Acesso em: 29 out. 2013. 